\title{
Participatory Action Research With Colombian Immigrants
}

\author{
Fabricio E. Balcazar \\ Edurne Garcia-Iriarte \\ Yolanda Suarez-Balcazar \\ University of Illinois, Chicago
}

\begin{abstract}
This article describes a participatory needs assessment process in which Colombian immigrants in Chicago collaborated with university researchers to identify their common concerns and implement self-help efforts to address some of their most pressing needs. A total of 261 Colombians completed a needs assessment survey, and 46 attended a public forum in which the issues were discussed and groups of volunteers were organized to coordinate and plan actions to address identified needs. Groups of volunteers conducted the research and developed a guide to health care and a guide to social services in the state of Illinois, which were widely distributed in the community. The participatory methodology appears to have effectively mobilized individuals who volunteered their time to help others-particularly newcomers who often find themselves at a loss to maneuver and understand a complex array of systems and services that are completely unfamiliar. Implications for future research are discussed.
\end{abstract}

Keywords: Colombian immigrants; needs assessment; participatory action research

\footnotetext{
Authors' Note: This study was funded, in part, by a grant from the National Institute on Disability and Rehabilitation Research (NIDRR), U.S. Department of Education, grant number H1333A040007. The opinions expressed here are the authors' and not necessarily those of NIDRR. The authors would like to acknowledge the collaboration of the Colombian Consuls of Chicago during the period of the study, Priscila Ceballos and Paulina Gomez, whose support was instrumental in the execution of the study. In addition, we want to acknowledge the leaders and members of the committees Dr. Carlos F. García, Lil Mejia, Dr. Tatiana Pardo, Claudia García, and Myriam Lucia Hincapié (Health); Oscar Gil, Maria Teresa Giraldo, Marcel Torres, Gloria Velez-Rendon, and Jairo Ospina (Social); and Nettie Lasko, Hilda Lozano, and Bibian Guevara (Immigration). We also appreciate the collaboration of the many Colombian residents who participated in the survey and meetings described in this study. Please address correspondence to Dr. Fabricio E. Balcazar, Department of Disability and Human Development (M/C 626), University of Illinois at Chicago, 1640 West Roosevelt Rd., Chicago, IL 60608; e-mail: fabricio@uic.edu.
} 
$\mathrm{O}^{\mathrm{n}}$ ne of the top Latino immigrant groups admitted into the United States are Colombians (Hofman \& Escala, 1999). According to estimates from the Colombian embassy in Washington, DC, there are approximately 1 million Colombians currently in the United States (1.3\% out of all the Hispanic/Latino population in the United States). In South Florida, Colombian Americans are the second largest Hispanic group (about 375,000); they have elected a Florida state representative and former Governor Jeb Bush appointed one Colombian American as a Broward County Court judge. Colombians also have state senators in South Carolina, Minnesota, and Rhode Island (Woods, 2007).

The U.S. Census identified 627,000 Colombians living in the United States in the year 2006 (Migration Policy Institute Data Hub, 2008a). O'Donnell and Batalova (2007) estimate that about $40 \%$ of the total immigrant population in the country is undocumented and unaccounted for. Using that estimate, approximately 250,000 Colombians are undocumented, which brings the total population close to the Colombian Embassy's total. The Migration Policy Institute Data Hub (2008b) reports that from 1990 to 2006, the U.S. Department of State allowed 292,856 permanent residents from Colombia (with a range from 9,966 cases in 1999 to 43,151 cases in 2006). In addition, there were 30,458 Colombian asylum seekers admitted into the United States from 1990 to 2004 (Migration Policy Institute Data Hub, 2008c). In fact, Colombia is the third country after China and Haiti in terms of the number of refugees and asylum seekers coming into the United States, with 2,964 in 2006 alone (O’Donnell \& Batalova, 2007).

Hofman and Escala (1999) found in a study conducted in New York and New Jersey that Colombian immigrants were more likely to have a better economic situation and higher level of formal education compared with other Latino immigrant groups. Despite this favorable situation, Hofman and Escala (1999) found that this group also has needs shared by other Latino immigrant groups, such as access to health care and social services. For instance, of those surveyed in their study, $41.9 \%$ lacked health insurance. In addition, they found that immigrants have strong ties to Colombia. This is reflected in the high rates of remittances to their relatives in Colombia (currently averaging $\$ 120$ per month per person) and a feeling that their emotional needs could be better fulfilled in their country. Related to this, Hofman and Escala (1999) found that Colombian immigrants in New York have a limited knowledge of local organizations and their participation in those organizations is low. Colombian immigrants also reported that they migrate to the United States seeking better economic and material conditions, which contribute to increased standards of living. In general, 
they were more likely to hold service jobs, be professionals and technicians, office workers, and merchants. They were also more likely to have better English conversational skills than other immigrant Latino groups in the United States. To address the needs of the Colombian community in New York and New Jersey, Hofman and Escala (1999) recommended more participation of the community in meetings with the consulate to develop an action agenda in order to generate more information about the community of Colombians in this country. This study used a participatory action research (PAR) methodology to identify the concerns of the growing Colombian community in the State of Illinois and mobilize volunteers and existing organizations to take action in coordination with the Colombian consulate of Chicago through a new initiative sponsored by the current government of Colombia called Colombia Nos Une (Colombia unite us).

Colombia Nos Une is an initiative sponsored by the Ministry of Foreign Affairs and coordinated by the Colombian embassies and consulates in countries with significant proportion of immigrants. The purpose of the program is to strengthen the ties within Colombians residing in communities outside of the country and promoting cooperation, solidarity, and voluntarism. The program encourages immigrants to organize associations and activities to preserve the cultural identity of the immigrants and their children. The ministry has hired a consultant that promotes the program and encourages community organizing in the United States. The Colombian community in Chicago has more than 40 years of experience in community organizing, with several social, cultural, and civic organizations that sponsor a number of programs and activities each year. A group of approximately 40 leaders and representatives from volunteer organizations-including the first author-met in Chicago with the Colombia Nos Une consultant to learn about the initiative. This group appointed a smaller group of five volunteers to coordinate the implementation process in Chicago. The authors proposed the participatory needs assessment methodology, described here, to identify the current community needs and promote action.

PAR has gained recognition in the social and health sciences as an effective research strategy to promote the active participation of consumers in the identification of their concerns and in the search for solutions and actions to address identified needs and improve their social conditions (Balcazar, Keys, Kaplan, \& Suarez-Balcazar, 1998). A PAR approach encourages self-help and promotes independence and self-reliance (Selener, 1997). The strategy can also be essential to identifying the needs of immigrant populations and promoting action and problem solving. 
A PAR approach to identifying the health needs and community needs of immigrant populations can also provide strong evidence for practice (Taylor, Braveman, \& Hammel, 2004) and increase the likelihood that services and programs will be sustained over time (Suarez-Balcazar, Martinez, \& CasasByots, 2005). It also facilitates ownership of the research and intervention, adoption of innovations, and aims at empowering individuals and improving social conditions (Balcazar, et al, 1998; Selener, 1997). Although PAR approaches have included both quantitative and qualitative methods, there is not one set of methodological strategies under PAR. The methodology used in this study, called the Concerns Report Method (CRM; Fawcett, Seekins, Whang, Muiu, \& Suarez-Balcazar, 1982; Suarez-Balcazar, 1998) is a participatory action-oriented strategy designed to identify issues, brainstorm solutions, and take action from the perspective of community members. Most needs assessment methodologies in the literature have focused on identifying needs but not necessarily on promoting action and problem solving as part of the method. In this study, we used a PAR approach that could easily be replicated with other immigrant communities. This study evolved from the collaboration between the local Colombian Nos Une coordinating committee and the Colombian Consulate in their desire to identify the most pressing needs of the Colombian immigrants residing in the Chicago area and promote action as recommended by the Hofman and Escala's (1999) study.

\section{The Concerns Report Method as a Participatory Action Research Approach}

The CRM is a systematic participatory process for setting agendas for community change from the perspective of those who share a common predicament (Fawcett et al., 1988; Fawcett et al., 1994; Suarez-Balcazar 1998; Suarez-Balcazar, Balcazar, \& Fawcett, 1992; Suarez-Balcazar, Balcazar, Quiros, Chavez, \& Quiros, 1995). The CRM goes beyond being a needs assessment methodology. It has been conceptualized as an agenda setting, capacity building, and empowering approach as participants take control of decisions and actions that affect their lives (Balcazar, Keys, \& Suarez-Balcazar, 2001). Prilleltensky (2001) asserts that a PAR approach to research emphasizes the praxis cycle of social action, which includes critical reflection, action planning, and implementation. This praxis cycle was built on Freire's (1970) praxis framework in which an ongoing interaction between reflection and action is achieved through a process of developing critical awareness within the community. The CRM incorporates the praxis 
cycle in the following phases: reflection on the values and central functions of the community; identification of community concerns; brainstorming of ideas and solutions; planning and taking action; and monitoring and feedback (adapted from Balcazar et al., 2001; Suarez-Balcazar, 1998). In this process, members of the community take an active role in the development of a community concerns survey through focus groups and interviews with leaders and service providers. During this process, a concerns survey tailored to the particular community is developed and distributed. Then the survey results are analyzed, shared, and discussed with the community members in public forums. During these meetings, participants discuss the dimensions of the issues and alternative solutions to address the identified concerns.

One of the products of the CRM is a prioritized list of strengths and needs to facilitate agenda setting that can inform policies, services, and programs. This list can be used to provide evidence for planning new services. Survey items have two dimensions-importance and satisfaction. Community strengths are considered survey items that the majority of participants rate high in importance and high in satisfaction, while concerns are survey items that the majority of participants rate high in importance and low in satisfaction (Fawcett et al., 1982; Suarez-Balcazar, 1998). The CRM has been used to identify community concerns of low-income families (Suarez-Balcazar, et al., 1995), Americans with physical disabilities (Suarez-Balcazar, Bradford, \& Fawcett, 1988), residents of a Costa Rican rural community (Suarez-Balcazar et al., 1995), and Latinos with disabilities (Balcazar et al., 2001) among other groups. Social validity and reliability of the CRM have been established. Schriner and Fawcett (1988) found overall high ratings of the helpfulness, completeness, and representativeness for a concerns survey developed by low-income families. Mathews, Petty, and Fawcett (1990) calculated a Spearman rank correlation between the responses of 405 subjects to the same survey items on a survey developed by people with disabilities at 18 -month intervals, finding highly consistent scores $(r s=.94, z=10.85, p<.001)$.

\section{Case Study}

\section{Project Collaborators}

The coordinating group included 4 females and 2 males, including the first author, Colombian immigrants of middle age, and all of them professionals who had been in the United States between 3 and 30 years. The 
group was appointed in December of 2005, by the Chapter of Colombia Nos Une in Chicago and collaborated with the local Colombian Consulate.

\section{Development of the Collaborative Partnership}

Following principles of university-community partnerships, the collaboration was based on principles of trust and mutual respect, open communication, reciprocal learning, and respect for diversity and different points of view, among others (see Suarez-Balcazar, Harper, \& Lewis, 2005). Partners held meetings alternating from the university site to the consulate and organizations or businesses from group members. The coordinating team included three leaders of grassroots organizations (one of them was a faculty member at a local college), one businessman, the first author, and one person who was a community trainer (English as a second language and leadership skills). What follows is a description of the CRM five phases and how they were applied in the context of the Colombian project.

\section{Concerns Report Method Methodological Phases}

\section{(a) Reflection on Values and Central Functions of the Community}

This phase requires the development of a matrix that allows the formulation of specific items for the concerns survey. The matrix was developed using two criteria: community functions and values. The coordinating group and the general Consul of Chicago met to identify community functions and values of relevance to the Colombian community of Chicago. Values such as justice, opportunity/access, and equality were identified as important. This group also identified the following community functions: education, employment, housing, social network, integration, consular services, health services, acculturation, English language, social services, contact with relatives in Colombia, and disability services.

\section{(b) Identification of Community Concerns}

Development of the concerns survey. Based on the matrix of values and community functions created during the first phase, a team of 10 leaders of various Colombian organizations, the researchers, and the Consul collaborated in the development of a preliminary list of survey items. The final survey was pilot tested with 4 members of the Colombian community. The final survey had a total of 37 items encompassing 3 items related to education, 7 related to employment, 2 to housing, 8 related to social networks, 4 
to health, 2 to social services, 4 to culture/acculturation, 3 to immigration, and 4 to contact with Colombia. A demographic section including 19 questions was added at the end of the survey. All the questions and survey instructions were created in Spanish. The survey included two types of questions for each item. The first question asked about the importance of a particular issue. The second question asked about the respondent's satisfaction with the issue. Both questions were rated on a 5-point symmetric differential scale, where 1 indicated not important or not satisfied and 5 indicated very important or very satisfied.

Survey distribution. The survey was distributed in 2 different formatspaper and Internet-with the purpose of reaching a larger number of respondents. Approximately 1,000 copies of the paper survey were distributed in the Colombian Consulate in Chicago, in nine Colombian commercial businesses (restaurants, bakeries, and shops), and in seven cultural and/or religious events organized by the Colombian community in Chicago over a period of 3 months. The sites were identified by the members of the coordinating committee and the surveys were distributed and collected by several volunteers. The Colombian Consulate in Chicago sent an email with a link to the Internet survey to a total of 3,500 people registered in the Consulate from 12 Midwest states. Only Colombians living in Illinois were asked to respond in order to facilitated direct involvement in the action phase (approximately 1,000 people in the list were from Illinois). Survey Monkey - an Internet software for survey distribution and data collection was used for the internet survey.

Survey collection and data analysis. Once the paper and internet surveys were collected, researchers used SPSS to enter and analyze the data. Cross tabulation of importance and satisfaction ratings for each item were calculated to examine the overall community concerns of the respondents. We also used descriptive statistics to report results.

Participants' characteristics. A total of 261 people responded the survey, 78 responded the paper survey, and 183 responded the Internet survey. The following data summarizes the demographic characteristics of the respondents (the data do not add to $100 \%$ because not all respondents answered all the questions). Participants were $44 \%$ female and $40.6 \%$ male, ranging from 18 to 83 years of age, with an average age of 38 years. A total of $63 \%$ had Colombian citizenship, 4\% American and 10\% dual citizenship. Almost a third of the respondents were originally from Bogotá (the capital 
of Colombia), $27 \%$ were from the two second largest cities in Colombia (Medellin and Cali). Of the total number of respondents, 58\% came to this country between 1993 and 2006. However, 1999 was the year in which more people from this sample came, which represents the mode. Among the main reasons to migrate to the United States were work (23.4\%), education (20.69\%), and quality of life improvement $(11.11 \%)$. More than half of the respondents (54.79\%) reported work as their main occupation in the United States. Of the people who were working, $18.8 \%$ worked in service industries, $11.5 \%$ were professionals, $11.1 \%$ were laborers, $5.4 \%$ worked in education, and $53.3 \%$ did not report their occupation. Of those who worked, $65.73 \%$ had a full time job. In terms of education, $51 \%$ of the respondents had studied in Colombia, and of those, $70 \%$ had college education in Colombia. Up to $40 \%$ reported having an advanced knowledge of the English language.

Concerns and strengths. Items rated high in importance and low in satisfaction were classified as concerns, while items rated high in satisfaction and high in importance were classified as strengths. These results are listed in Table 1. The most common identified concerns were the lack of knowledge about low cost or free health services, information about immigration, access to health services, knowledge about procedures and regulations to start business, availability of a social network, and knowledge about Colombian organizations in Illinois. Respondents also identified several strengths. Items rated by participants as high in importance and high in satisfaction were considered strengths. The most commonly identified strengths included contact with family in Colombia, ability to survive in the United States, preservation of Colombian culture in their families, knowledge about opportunities and resources to learn English, and equal treatment on the job.

Concerns and strengths were also analyzed by gender (males/females) and the type of survey response (Internet/paper). Analysis of strengths and concerns identified by these groups were conducted due to the existing differences between Colombian men and women (Hofman \& Escala, 1999) and the digital divide between economic classes. No significant differences were observed in strengths and concerns identified by males and females. However, there were differences in the concerns identified by people who responded to the Internet survey compared with the paper survey. For example, one of the top concerns identified by respondents who answered the paper survey was the need for a Colombian association of traders. This was not a concern for the general population or when we analyzed 


\section{Table 1}

\section{Strengths and Concerns of the Colombian Community in Illinois}

\begin{tabular}{lcc}
\hline Issues & $\begin{array}{c}\text { Percentage } \\
\text { Level of } \\
\text { Importance }\end{array}$ & $\begin{array}{c}\text { Percentage } \\
\text { Level of } \\
\text { Satisfaction }\end{array}$ \\
\hline Concerns of the Colombian community in Illinois & 90.63 & 46.93 \\
1. Knowledge of low cost or free health services & 94.37 & 53.86 \\
2. Information on immigration & 95.66 & 56.93 \\
3. Access to health services & 87.82 & 46.52 \\
4. Knowledge of procedures and regulations to & & \\
$\quad$ do business & 86.42 & 44.97 \\
5. Having a social network & 84.13 & 42.42 \\
6. Knowledge on the Colombian organizations in & & 78.52 \\
$\quad$ Illinois & & 75.00 \\
Strengths of the Colombian community in Illinois & 96.18 & 72.86 \\
1. Contact with your family in Colombia & 95.60 & 69.67 \\
2. Your capacity to survive in this country & & \\
$\quad$ (United States) & 93.26 & 67.19 \\
3. Preservation of the Colombian culture in & & 65.60 \\
$\quad$ your family & 91.83 & \\
4. Knowledge of opportunities and resources to & & \\
$\quad$ learn English & 92.96 & \\
5. Continuation of your education & 94.77 & No discrimination against at the job
\end{tabular}

Note: Percentages indicate the level of importance and satisfaction in a scale from 1 to 100 . Note that they do not indicate the percentage of people. These percentages were obtained using the following formula: $\{[5 n(5)+4 n(4)+3 n(3)+2 n(2)+1 n(1)] / N(5)\} \times 100=$ Importance or satisfaction, where $5 n, 4 n, 3 n, 2 n$, and $1 n$ are the number of people who selected each of the 5 choices for satisfaction or importance in the respective scales.

a. During the public forum participants decided to collapse issues 5 and 6 into one concern.

separately males and females. On the other hand, two of the top concerns identified by the general sample were not among the top 10 concerns for this group: procedures and regulations to start business (item 8 ) and information on immigration (item 31 ). This led us to a secondary analysis of demographic characteristics seeking the differences of these two groups using a chi-square test. We found that there were significant differences in occupation, education, and level of English. Internet surveyors were more likely to be professionals and educators than laborers or people working in service industries $\left(\chi^{2}=15.118, p<.05\right)$, they were people who had college education $\left(\chi^{2}=15.388, p<.05\right)$, and had advanced knowledge of English language $\left(\chi^{2}=8.879, p<.05\right)$. 


\section{(c) Brainstorming of Ideas and Solutions}

Data sharing at public forum. The results of the survey were summarized in a brief report and shared at a community public forum with a total of 46 people participating ( 30 women and 16 men). The majority of the participants (27) represented associations that were active in Colombia nos une. There were five doctors who also filled out the survey and attended because they were interested on health issues and six individuals that came because they filled out the survey and wanted to participate in the forum. In addition, there were five people representing the Colombian Consulate, two people representing the university, and a member of the local press (these individuals were the only ones who have not filled out the survey). The public forum was conducted at a local university. During the 2-hour public forum, the Colombian community was invited to celebrate the strengths, discuss the dimensions of the identified concerns, brainstorm possible solutions, and identify actions/next steps. Identified issues were assigned to separate tables, were volunteers were asked to join according to their personal interests and expertise. Many compelling proposals to address identified needs emerged in the public forum. Some of the proposed solutions included: to develop a directory of bilingual health services for Hispanic families; to train a group of volunteers on immigration issues to provide accurate information to the Colombian community; to create paid positions to provide accurate information to the Colombian community; and to secure an information office at the consulate. Table 2 provides a summary of a sample issue discussed during the public forum. A report summarizing the top strengths and concerns, the dimensions of the issues and the ideas suggested during the public forum was developed and presented to the leaders of the volunteer organizations and personnel from the Colombian consulate. This report was also posted in the consulate Web page.

\section{(d) Planning and Taking Action}

Development of planning committees. A direct result of the identification of local community needs and concerns was the establishment of four action planning committees to address the needs of the community. After the issues were discussed and brainstormed solutions were considered during the public forum, poster paper was taped to the walls, one for each of the four main concerns (the two issues related to health care were combined into one single action committee), and participants were asked to identify an issue they wanted to work on and sign-up under that topic. As a result of the public forum, community members signed up for working committees to take action on identified topics/strategies. Community leaders and 


\section{Table 2}

\section{Summary Discussion: Dimensions and Solutions of a Sample Issue}

Issue: Immigration

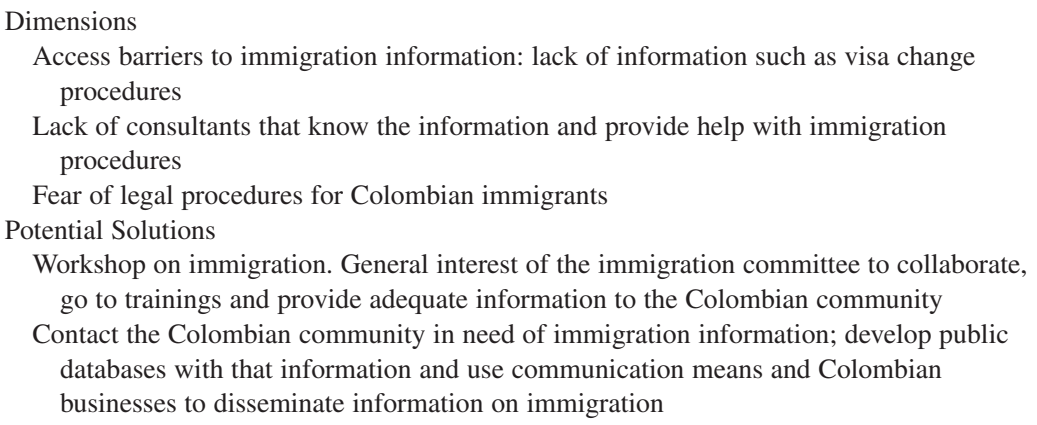

members of the coordinating committee facilitated and chaired the working committees. The university researchers provided leaders with an action guide containing information on how to organize committees and orient them toward effective ways for taking action, running meetings, and establishing good communication with committee members.

Three of the committees engaged in actions to address concerns identified by respondents: the Health Committee, the Immigration Committee, and the Social Network and Colombian Organizations Committee. The committee on small business development never met because the person in charge did not follow-through and the association leaders were not personally interested.

The Health Committee was coordinated by a local doctor and included another doctor, a health services and outreach specialist from a local hospital who was assigned to work with the committee by the CEO who was a Colombian, and two community members who worked in health-related occupations. The committee decided to produce a guide for health services in the state of Illinois and met regularly once a month to share progress. The task was complex given the multiplicity of services and various eligibility criteria for different health programs in the state. The committee decided to focus first on identifying programs for low-income individuals and/or services for undocumented residents of the state. Committee members also identified whether those services were available in Spanish and the contact information for each service. They also identified clinics and hospitals that specialized in providing services to the Latino community of Chicago at low cost. Once the information was compiled, committee members decided 
on a format for dissemination. With the assistance of local businesses that sponsored the printing cost, 5,000 copies of the health care brochure were printed and distributed to the Colombian community during several large events celebrating the independence of Colombia. Future plans of the committee include generating a list of Colombian doctors and their specialties in the Chicago area and posting the health brochure in the Colombian consulate Web page.

The immigration committee involved four individuals who represented several organizations interested in serving refugees or immigrants. One of them worked in the office of the Attorney General of Illinois and she took the lead in organizing a workshop open to the Colombian community on immigration laws. Three experts on immigration issues-including an immigration lawyer, a staff member from the office of Senator Richard Durbin of Illinois who was involved in immigration reform, and an advocate from a local immigrant support organization presented information and answered questions from an audience of approximately 40 people who attended the event. The committee conducted another information forum in the fall of 2007 and is also preparing information to be posted on the Consulate's Web page regarding immigrant's rights.

The Social Network and the Colombian Organization Committee consisted of five volunteers and a staff member from the Colombian Consulate who was a social worker hired to assist immigrants with their concerns and adjustment issues. This was one of the concerns identified in the survey and addressed by the consulate with the support of the ministry who provided the additional funds for the position in order to improve the services to the community. The committee developed a brochure with contact information about a variety of social services agencies or programs available to immigrants including: shelter for victims of spousal abuse; drug and alcohol counseling; local programs for learning English; services for children, adolescents, and people with disabilities. One of the committee members, who is a businessman, sponsored the printing of 10,000 copies of the brochure, which were widely distributed during the Colombia's independence celebrations and fairs in July of 2007. The committee is also planning to post the brochure on the consulate's Web page. As with the health services brochure, the consulate is distributing copies of these brochures to anyone interested or requesting services.

\section{(e) Monitoring and Feedback}

Colombia Nos Une in Chicago created a coordinating committee to monitor the activities of the independent committees and continue to plan 
activities and services for the community. The committee has the list of issues identified in the participatory needs assessment and as the initial needs are addressed, the other top needs identified become a priority for further activities. In particular, the committee is interested in pursuing the needs identified by the individuals who responded using the paper copies, which differ somewhat from the electronic responses. The coordination and expansion of the activities from the multiple Colombian organizations in Chicago is also a long-term goal of the group. Chicago is one of the cities in which Colombian immigrants are best organized and the Colombian community is proud of their organizing and entrepreneurial history.

\section{Conclusion}

This article illustrates a PAR approach in collaboration with Colombian immigrants in which participants formulated their concerns, ideas for improvement, and implemented action strategies. The needs assessment phase yielded an agenda of concerns providing the basis for the community to organize its efforts with the goal of addressing the top concerns identified and eventually improving the quality of life of new or recent Colombian immigrants. The needs assessment process became a catalyst for change.

During the implementation of the CRM, several leaders of existing Colombian organizations helped identify the key community functions and values, assisted in the development of the survey and in the discussion of the issues during the public forum, and participated actively in the action committees. The Colombian Consulate provided logistical support and the consul used her leadership to mobilize and involve the leaders and volunteers from the community. The university researchers were able to provide their knowledge of the participatory needs assessment methodology and facilitate the community organizing process. The participatory approach described in this article provided a process for the Colombian community in Chicago to come together and identify issues they care about, becoming actively involved in the analysis of contextual sociocultural issues important to them, and taking actions to address some of their most pressing needs. This methodology can be adapted to other immigrant groups (see Suarez-Balcazar, 1998).

There are several limitations of this study worth discussing. First, the response rates were somewhat low in part because we relied on volunteers and the goodwill of business owners to collect the paper surveys, many of which were never actually distributed to people. The internet survey had a 
better response rate because it is easy to distribute but it has its challenges as explained next. Second, there were significant differences in the type of individuals who responded to each version of the survey. It looks like the individuals that were more educated were more likely to be registered in the Web list from the consulate and therefore their responses were different from those who responded using the paper surveys. Future research should make more effort to increase the response rate to the paper survey, because those may reflect the needs of more recent immigrants. Third, and related to the second limitation, the needs identified in the paper surveys although similar to the other group had some differences that were not addressed. Future research should attempt to address the top needs identified by each mode of data collection. In addition, future research may try to replicate the process in communities with less organized immigrant communities to further validate the effectiveness of the participatory strategy. Finally, it may be useful to examine the reasons for participation of the various leaders and volunteers. Qualitative interviews with some of the key stakeholders could help identify motivational factors for participation or not. In conclusion, Colombia Nos Une in Chicago, became a catalyst for the leaders of the community to show their solidarity and desire to assist those most in need.

\section{References}

Balcazar, F., Keys, C., Kaplan, M. A., \& Suarez-Balcazar, Y. (1998). Participatory action research and people with disabilities: Principles and challenges. Canadian Journal of Rehabilitation, 12, 105-112.

Balcazar, F., Keys, C., \& Suarez-Balcazar, Y. (2001). Empowering Latinos with disabilities to address issues of independent living and disability rights: A capacity building approach. Journal of Prevention and Intervention in the Community, 21, 53-70.

Fawcett, S. B., Seekins, T., Whang, P., Muiu, C., \& Suarez de Balcazar, Y. (1982). Involving consumers in decision-making. Social Policy, 13, 36-41.

Fawcett, S. B., Suarez-Balcazar, Y., Whang-Ramos, P. L., Seekins, T., Bradford, B., \& Matthews, R. M. (1988). The concerns report: Involving consumers in planning for rehabilitation and independent living services. American Rehabilitation, 14, 17-19.

Fawcett, S. B., White, G. W., Balcazar, F., Suarez-Balcazar, Y., Mathews, M. R., \& Paine, A. (1994). A contextual-behavioral model of empowerment: Case studies involving people with disabilities. American Journal of Community Psychology, 22, 471-96.

Freire, P. (1970). Pedagogy of the Oppressed. NY: Continuum International.

Hofman, A., \& Escala, Z. (1999). The Colombian community in metropolitan New York; Who are we and where are we going? Migration World Magazine, 27, 13-17.

Mathews, R. M., Petty, R., \& Fawcett, S. B. (1990). Rating consistency on successive statewide assessments of disability concerns. Journal of Disability Policy Studies, 1, 81-88. 
Migration Policy Institute Data Hub. (2008a). United States: Stock of foreign-born population by country of birth, 1995 to 2006. Retrieved on August 30, 2008, from http://www.migrationinformation.org/datahub/countrydata/country.cfm

Migration Policy Institute Data Hub. (2008b). United States: Inflow of foreign-born population by country of birth, 1986 to 2006. Retrieved on August 30, 2008, from http://www .migrationinformation.org/datahub/countrydata/country.cfm

Migration Policy Institute Data Hub. (2008c). United States: Annual number of asylum applications by nationality, 1991 to 2004. Retrieved on August 30, 2008, from http://www .migrationinformation.org/datahub/countrydata/country.cfm

O’Donnell, K., \& Batalova, J. (2007, December). US in focus: Spotlight on refugees and asylees in the United States. Migration Information Source. Washington, DC: Migration Policy Institute. Retrieved August 30, 2008, from http://www.migrationinformation.org/USFocus/ display.cfm? $\mathrm{ID}=664$

Prilleltensky, I. (2001). Value-based praxis in community psychology: Moving towards social justice and social action. American Journal of Community Psychology, 29, 747-778.

Schriner, K. F., \& Fawcett, S. B. (1988). Development and validation of a community concerns report method. Journal of Community Psychology, 16, 306-316.

Selener, D. (1997). Participatory action research and social change. New York: Cornell Participatory Action Research Network.

Suarez-Balcazar, Y. (1998). Un modelo contextual de incremento de poder comunitario aplicado a una poblacion Hispana en los Estados Unidos. In A. M. Gonzalez (Ed.), Psicologia Comunitaria: Fundamentos y Aplicaciones (pp. 107-119). Madrid, Spain: Universidad Autonoma de Madrid.

Suarez-Balcazar, Y., Balcazar, F. E., \& Fawcett, S. B. (1992). Problem identification in social intervention research. In F. Bryant, J. Edwards, R. S. Tindale, E. J. Posavac, L. Heath, E. Henderson, \& Y. Suarez-Balcazar (Eds.), Methodological issues in applied social psychology (pp. 25-42). New York: Plenum Press.

Suarez-Balcazar, Y., Balcazar, F. E., Quiros, M., Chavez, M., \& Quiros, O. (1995). A case study of international cooperation for community development and primary prevention in Costa Rica. In R. E. Hess \& W. Stark (Eds.), International approaches to prevention in mental health and human services (pp. 3-23). New York: Haworth Press.

Suarez-Balcazar, Y., Bradford, B., \& Fawcett, S. B. (1988). Common concerns of disabled Americans: Issues and options. Social Policy, 19, 29-35.

Suarez-Balcazar, Y., Harper, G., \& Lewis, R. (2005). An interactive and conceptual model of community-university collaborations for research and action. Health Education and Behavior, 32, 84-101.

Suarez-Balcazar, Matinez, L., \& Casas-Byots, C. (2005). A participatory action research approach for identifying the health service needs of Hispanic immigrants: Implications for occupational therapy. Occupational Therapy in Health Care, 19, 145-163.

Taylor, R. T., Braveman, B., \& Hammel, J. (2004). Developing and evaluating communitybased services through participatory action research: Two case examples. American Journal of Occupational Therapy, 58, 73-82.

Woods, C. (2007, September 23). US Colombians seek more political cloud. The Miami Herald. Retrieved August 30, 2008, from http://www.latinamericanstudies.org/latinos/colombians-07 .htm 
Fabricio E. Balcazar, $\mathrm{PhD}$, is a professor in the Department of Disability and Human Development and director of the Center for Capacity Building on Minorities with Disabilities Research at the University of Illinois at Chicago. He has conducted research over the past 25 years on the development of systematic approaches for promoting the empowerment of minorities and underserved populations, including Latinos and African Americans with disabilities and their families. He is a fellow of the American Psychological Association and a former performer of serenades.

Edurne García Iriarte, MS, is a doctoral candidate in the disability studies program at the University of Illinois at Chicago. She obtained her BA in psychology from the University of Salamanca (Spain). Her dissertation focuses on the participation of adults with intellectual disabilities in empowerment evaluation and self-determination. In her free time, she enjoys reading novels, going to art exhibits, and watching films.

Yolanda Suarez-Balcazar, $\mathrm{PhD}$, is a professor and head of the Department of Occupational Therapy at the University of Illinois at Chicago. Her research examines service providers' capacity for evaluating the impact of their programs and providing evidence-based, culturally competent services to ethnically diverse populations with disabilities. She is a community psychologist and a fellow of the American Psychological Association. For leisure she enjoys watching her kids' sports competitions, jogging, and traveling abroad. 